\title{
Editorial
}

\section{Tricky Times}

\author{
Lance Gunderson $^{1}$ and Carl Folke ${ }^{2,3}$
}

\section{INTRODUCTION}

In many ways, the year 2011 has been extraordinary in terms of the frequency and scales of crises. We have seen exogenous environmental events such as the tsunami in the Pacific to floods in Brazil, Thailand, and the Philippines to cyclones in the heartland of the United States resulting in massive loss of lives and property. These variations in weather have not been unusual in their occurrence, but have been unusual in their impact to the human systems. In other words, these events have tested the resiliency of humans and their infrastructure. The other type of crises has been largely endogenous, namely social unrest, led by technologies that have created more connectivity, witnessed in the Arab Spring and continued with the Occupy movement. Although the longer term results are still uncertain, there can be little denying that the past year has been one of dramatic changes. The financial crisis still remains and there is overspending in many countries challenging collaborations of whole regions, like Europe. Understanding the linkages between the natural and human systems is a key theme of this journal. The journal also publishes work that attempts to explain abrupt and surprising change and how periods of gradual change can be prepared for or overwhelmed by external events.

Much of resilience theory is about explaining shifts in controlling variables, whether they are ecological or social and interacting. To understand such shifts either in theory or in practice, as we are observing this year, involves questioning the extant boundaries and the processes that determine those boundaries. But this is where it gets tricky.

Over long histories and through many cultures, humans have developed stories about key individuals, both real and imagined, who play critical roles transforming systems after crises. One such group is called tricksters because of their unexpected and surprising behaviors. Such individuals test existing boundaries and rules, but with positive results. These tricksters are so common that the myths appear universal. Native Americans personified these traits in the spirits of coyotes and ravens. One Greek myth had Prometheus steal fire from the gods, which has become a metaphor for the development and application of technology by humans. In more modern settings, the groups such as Ken Kesey and the Merry Pranksters started a cultural revolution against the mores of the early 1960s in the United States. Lisbeth Salander, the heroine of Stieg Larsson's Girl with the Dragon Tattoo trilogy, is one of the more recent stories depicting such roles in fiction.

We emphasize the creative roles of tricksters in questioning boundaries and producing positive outcomes, and not the mean and malicious sides of such actions. Their ability to innovate and find clever paths while navigating complex problems is a trait that is similar to the scholars that contribute to this journal. The intelligent, skillful, creative, and positive attributes characterize much of the scholarship within this issue, as described in the next section.

\section{This issue}

In this, the fourth issue of 2011, we close the 16th volume of Ecology and Society. Over the past six months, including both the third and fourth issues, we published more than 45 peerreviewed independent articles.

We invite the reader to explore the diversity of the articles in these issues. Although we cannot do justice to the full range of topics, the articles are an impressive array of studies of the theory, practice, and management of complex systems of people and nature. Some of the articles are flavored by highly practical considerations, such as adaptive management, buffer zones, restoration, and reconciling multiple human values of ecosystems. Others are more analytic, such as the development of new models for linking the ecological and social dynamics, or describing how humans have directly and indirectly modified ecosystem structures and processes, from large mammals in Canada to livelihood and vulnerability analyses. A few articles present trajectories of coupled systems over long-term historical dimensions and how those pasts could help us build better futures. There are a few articles that contribute to our understanding of the resilience of cities and urban areas. Other themes emerge from the suite of articles that contribute to understanding and seeking sustainable outcomes.

We continue to publish as many, or more, articles in special features, and currently have 11 such features ongoing. They all integrate the ecological and human dimensions around complex resource systems.

The special feature on Resilience and Vulnerability of Arid and Semi-Arid Social Ecological Systems is closed. The 
editors and authors address how livelihoods can be made more robust and resilient in one of the most vulnerable ecosystems on the planet. A combination of methodological and interdisciplinary approaches will be needed to address the myriad of social, economic, political, and environmental issues that confront these systems that are home to one third of the human population on the planet.

We are most grateful for the hard work of all that contribute to Ecology and Society. We cannot thank enough the dedicated editors and reviewers who give of their precious time to support this work. We thank the Resilience Alliance for fiscal and administrative support. Finally, we thank the staff, Adele Mullie, Jennifer Miner, and Jennifer Mullie, who have managed the day to day operations, and the copy editors who improve all of our writing but are rarely acknowledged. We wish all of them a relaxing break for the Christmas season and the remainder of 2011. We are already looking forward to an exciting 2012 amazed by the submissions and the novel, creative, and rigorous scholarship that appears in our journal.

Responses to this article can be read online at:

http://www.ecologyandsociety.org/voll6/iss4/art31/

responses/ 